\title{
Towards a Risk Based Cooperative and Collaborative Culture - the Attitudinal Elements and Influences that Shape Our Behaviour and Public Opinion
}

\author{
Richard Bradford-Knox
}

RBK Consultants, United Kingdom

\begin{abstract}
The focus of this paper is on attitudes and behaviour and the constructs they are influenced by. Attention drawn to the key attitudinal elements that influence actual behaviour. Using a constructivist approach the paper is based on a review of the extant literature including the author's previous work. The paper identifies the key constructs that form attitudes and behavioural intent, how they can be influenced by various types of intervention, including nudging, to have the potential for a functional rather than dysfunctional outcome. The literature is wide ranging, but it is possible that some key elements and approaches of the various cultures may have been overlooked. Therefore, researchers are encouraged to test them in further research. Case studies of various organisations, cultures and experiences are of potential value. The paper includes implications for the development and constructing an effective public risk-based culture by working towards a need to identify and emphasize the key elements that contribute to our attitudes and subsequent behaviour.
\end{abstract}

Keywords: Culture; Cooperation; Collaboration; Attitudes; Post-Truth; Interventions; Nudges; Behaviour 


\section{Introduction}

At the time of writing the world is locked in battle with an invisible enemy that is deadly and proving exceedingly difficult to control. Rarely in the history of humankind has the need for a collective risk-based culture or cultures of cooperation and collaboration been so important and necessary in combating the spread of infection and protecting the vulnerable.

In previous research Bradford-Knox and Neighbour (2020) proposed that all health and safety cultures, including food safety management, share the same fundamental attitudinal and behavioural influences. This article enlarges on this proposal by addressing some of the attitudes and behaviours that are resistant to any cooperative effort required to prevent or control the spread of the virus and how they can potentially be addressed.

\section{Background}

A characteristic aspect of risk in a complex and modern society is the nature and degree of the public response that is sometimes significantly at variance with objective assessments of risk (Cronemyr et al., 2017). This apparent disregard of the risks, government and scientific advice has been demonstrated recently by instances where members of the public have ignored the advice or guidance of government and science. This refusal to cooperate includes attributing the pandemic to something that appears from the scientific evidence to be completely unrelated. For example, by ascribing the cause of Covid-19 to transmissions from 5G wireless masts (Bruns et al., 2020; Jolley and Paterson, 2020). Further examples are the people who refuse to have vaccinations to protect themselves and their children from infectious diseases (Levy, 2017).

As reported by the BBC News (2020) there have been occasions where many people have ignored government guidance, legal requirements, and the law by gathering in large numbers. These behaviours have the potential to increase the risk of the hazard spreading among the general population more quickly. Many sources attribute this type of behaviour to the world having entered a 'post-truth' era. Post-truth was the Oxford Dictionaries Word of the Year 2016 (Oxford Languages, 2020). Post-truth is an adjective defined as 'relating to or denoting circumstances in which objective facts are less influential in shaping public opinion than appeals to emotion and personal belief' (Levy, 2017).

It is claimed that this is not because people no longer care about the truth, but because the beliefs of many are not responsive to the best evidence. It has been suggested that these changes can be from people's psychology e.g., Greater anxiety might make more people more susceptible to affective influences and less susceptible to argument or it might arise from changes in the external environment e.g. the decline of the traditional press and the rise of fake news sites (MacKenzie and Bhatt, 2020)

These factors can also lead to a lack of trust. Trust is the central construct to any form of successful cooperation and collaboration. Research indicates that trust matters more

International Journal of Management and Applied Research, 2020, Vol. 7, No. 4 
Towards a Risk Based Cooperative and Collaborative Culture - the Attitudinal Elements and Influences that Shape Our Behaviour and Public Opinion

in situations of conflicting interests, and it matters less in situations of corresponding interests (Balliet and Van Lange, 2012). The case of this pandemic demonstrates that there are potentially many corresponding interests regarding the health and well-being of everybody, but also some conflicting ones about business and economic interests, i.e. businesses unable to operate, and people who have lost their jobs. This has been demonstrated by disagreement between local government and national governments over control policies and requirements for controlling the spread of the pandemic. The differences of opinion being the balance between the health measures felt necessary to control the spread of the virus and concerns about the economic effects on businesses and jobs (Fana et al., 2020; Giammetti et al., 2020; Strange, 2020).

In accordance with the above the conceptual structure the flow chart (Bradford-Knox and Neighbour, 2020) needs to include more of the influences and interventions that can shape public culture or cultures (see Figure 1).

It is proposed therefore that in order to overcome cases of non-acceptance of the evidence and lack of trust the use of Nudge Theory or 'nudging' is utilized as well as government interventions and guidance such as legal requirements on travel, meeting with members of other households (see www.gov.uk/coronavirus).

A 'nudge' is essentially a means of encouraging or guiding behaviour without telling or forcing people, and ideally without the need for big incentives, sanctions, or changes in the law (Local Government Association, 2013). The objectives of nudges being to persuade people to act in a certain way rather being forced into it. Freedom of choice is preserved.

Nudging has been be used by many organisations for different purposes including the UK government in relation to the current pandemic alongside other messages and legal requirements to encourage responsible behaviour by the public. Nudges mean thinking harder about the way people approach decisions and using those insights to design policy (Local Government Association, 2013).

As described by the Nuffield Council on Bioethics ladder of intervention, there are other forms of intervention and types of nudges (Local Government Association, 2013, page 3$)$ :

\section{Smacks:}

Eliminating choice - Banning goods or services such as restriction on smoking in public places.

\section{Shoves:}

Financial disincentives - Taxation on cigarettes.

Restricting choice - Banning takeaways setting up close to schools.

\section{Nudges:}

Provision of information - Calorie counts on menus.

Changes to the environment - Designing buildings with fewer lifts.

International Journal of Management and Applied Research, 2020, Vol. 7, No. 4 
Towards a Risk Based Cooperative and Collaborative Culture - the Attitudinal Elements and Influences that Shape Our Behaviour and Public Opinion

Changes to default - Making salad the default side option instead of chips.

Use of norms - Providing information about what others are doing.

Sunstein (2014) describes nudges as liberty preserving approaches that steer people in particular directions but allow them to go their own way and give many examples including text reminders about events for example medical appointments and "apps" that tell people how many calories they ate during the previous day.

According to Levy (2017) nudges can be controversial for several reasons . The central reason is that they are unacceptably paternalistic and therefore threaten autonomy of agents and he proposes the use of what he describes as nudges to reason. He argues that these nudges do not threaten our autonomy. Interventions into decision making and belief formation threaten our autonomy. Nudges to reason do not bypass our capacities for deliberation. Rather they address themselves to capacities that are partially constitutive of our reasoning.

For example, Preston City Council uses nudges in its Food Safety Compliance Strategy in order to elicit a better response from food businesses and get them to think more about their situation (Bradford-Knox et al., 2016). In their experience many food businesses had a negative attitude towards council enforcement officers. Their attitude was that the officers were only there to catch them out and if possible close them down. In fact, the council's objectives were just the opposite. Successful businesses are of more value to the city than unsuccessful ones. To be successful they want to persuade the businesses to cooperate, follow the regulations and where possible to improve standards.

In order to overcome this negativity, Preston City Council sent out letters inviting the Food Business Operators (FBOs) to have an informal chat about their circumstances. The letters included a statement: '93\% of businesses in Preston have a rating 3 or above ( 5 is top rating). We are wondering how being in the $7 \%$ could be useful to you?' This led to an improved response from the businesses of $34 \%$. With some letters they also sent out photographs of the businesses taken on 'wet miserable days' that gave the appearance of being not very attractive premises. This produced a further increased response of $42 \%$. Both these nudges suggested or implied that by working more closely with the council they could improve their levels of compliance with food hygiene standards and become more successful (Bradford-Knox et al., 2016).

\section{Flow Chart}

\subsection{Constructs}

The Flow Chart presents a concept of how our attitudes and consequently subsequent behaviours are formed in what Ajzen and Fishbein (1980) describe as 'Background Factors '.

We do not attempt to address or describe all the constructs that contribute to our attitudes and behaviour. Each Critical Point is a step in the mental processes that can lead to a Functional, Resilient and Collectivist Culture.

International Journal of Management and Applied Research, 2020, Vol. 7, No. 4 


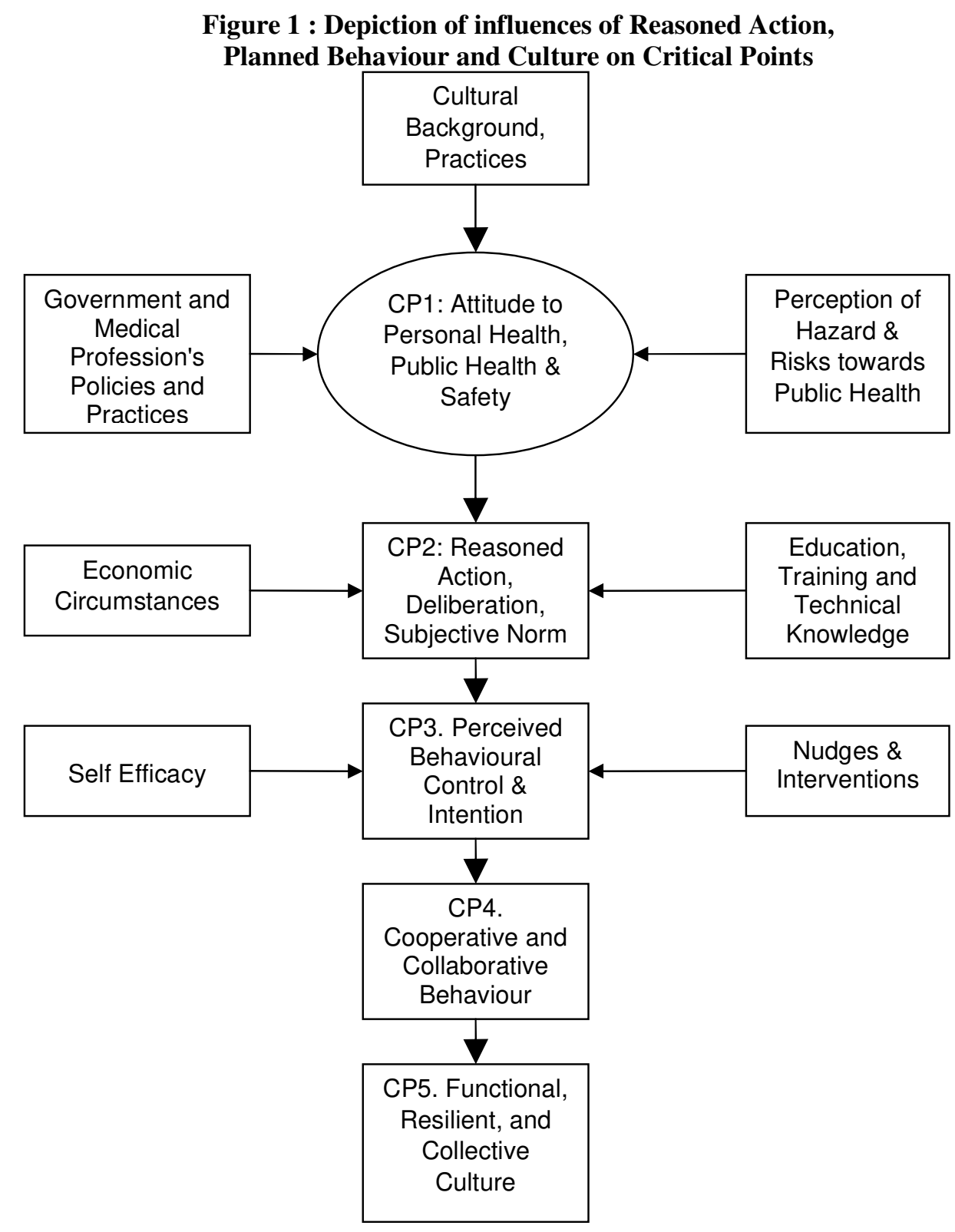

Cronbach and Meehl (1955) define a hypothetical construct as a concept for which there is not a single observable referent, which cannot be directly observed, and for which there exist multiple referents. For example, a fish is not a hypothetical construct because, despite variation in species and varieties of fish, there is an agreed upon definition for a fish with specific characteristics that distinguish a fish from a bird. Furthermore, a fish can be directly observed. On the other hand, a hypothetical construct has no single referent; rather, hypothetical constructs consist of groups of functionally related behaviours, attitudes, processes, and experiences. Instead of seeing intelligence, love, or fear we see indicators or manifestations of what we have agreed to call intelligence, love, or fear. 


\subsection{Cultural Backgrounds and Practices}

There has been a much research into culture and types of culture with a variety of similar or related definitions. Ehrengren and Hornsten (2011), describe culture as the collection of values, beliefs, behaviours, customs, and attitudes that distinguishes a society.

According to Cronemyr et al. (2017), organisational culture is a structure of shared values and common values are the very core of cultures and of organisational cultures.

A strong organisational culture is formed by a great level of agreement about what is valued and a high level of strength about those values. It is hard to define it in all its complexity and very challenging to change once it has become established. The tendrils of culture spread throughout an organisation affecting everything that happens and effecting changes on people as they join and live within an organisation (Kane and Taylor, 2018).

According to Irwin (1996), intellectual communication occurs between individuals and small groups of people who possess their own unique characteristics. Some characteristics are culturally induced and can be understood in terms of cultural heritage and positioning. It would be a mistake to make assumptions that people from certain cultures are all going to behave in the same way. However, it is helpful or useful, when communicating with people from different cultures, to be aware of attitudes and behaviours that may be common to those cultures.

With this knowledge we can, if necessary, moderate our own behaviour in order to communicate more effectively, not cause offence and enlist their cooperation (Bradford-Knox, 2008).

According to the theories and findings of Hofstede (2001), one of the facets of cultural background of some societies is whether they are individualistic or collectivist. This is described as the extent to which an individual expects personal freedom versus acceptance of responsibility to family, tribal groups or nationalities. It is about being one's self, having self-reliance or self-interest, self-directed or self-oriented versus being other-directed, competitiveness versus co-operation, and having concern for others. Hofstede's research, which addressed societies on a macro level, inferred that certain societies or groups of people are more cooperative in their behaviour than others. In other words, they are less motivated by self-interest than by the interests of the society or group they are living or working in.

\subsection{Hazards and Risks}

According to the Health \& Safety Executive (2001) the identification, analysis and our perceptions of hazards and risks have become fundamental to all organisational and safety cultures. This includes health and safety regulations.

The term 'risk perception' is actually a misnomer. It is not 'risk' per se that is perceived but hazards rather an abstract concept of 'risk' that people appear to

International Journal of Management and Applied Research, 2020, Vol. 7, No. 4 
evaluate. Risk perception is thus the study of people's beliefs, attitudes, judgements and feeling about hazards, danger and risk-taking, within the wider context of social and cultural values. Knowledge about hazards and risks maybe a determining feature of attitude in relations to risk but are also likely to be influenced by social and cultural factors. In addition, attitudes to safety will be constrained by the values, norms, rules and regulations that the system has in place. In combination all these factors will reflect in the 'safety climate' or 'culture' of the organization (Mearns and Flin, 1995).

\subsection{Critical Points (CP) in Flow Chart}

CP 1: Attitudes and Behaviour

Attitude is described as a way of thinking or feeling about someone or something. Opinion is described as a personal view not necessarily based on fact or knowledge and for this research it is understood as a way of expressing a person's feelings and attitude to something or about someone (Oxford English Dictionary, 2020).

According to Medeiros et al. (2004) attitude is also a precondition for behaviour change, is abstract and not measurable, but evokes a measurable or observable response. An attitude, whether positive, or negative, is learned through the environment and can be described and used to describe mental readiness to act and predict the likelihood that a person will be motivated to move to action.

\section{CP 2: Reasoned Action, Deliberation \& Subjective Norm}

The Theory of Reasoned Action (TRA) (Ajzen and Fishbein 1980) takes this a step further and describes attitude towards behaviour as a direct determinant of behavioural intention. The theory is that a person's attitude consists of 1) A belief that that particular behaviour leads to a certain outcome and 2) an evaluation of the outcome of that behaviour. If the outcome seems beneficial to the individual he or she may then intend to or actually participate in a particular behaviour.

Importantly to this type of study TRA also states that whether a person participates or intends to participate in certain behaviour is influenced strongly by the people around them. This concept is known as the Subjective Norm. Subjective norm is a person's perception of what others around them believe that the individual should do. This includes positive influences as well as negative ones e.g., post truth, fear and disbelief. The people influencing them may include friends or a peer group, family, co-workers and community leaders. This can also include social media contacts.

\section{CP 3: Theory of Planned Behaviour}

Ajzen (1991) extended TRA to the Theory of Planned Behaviour (TPB). TPB adds the concept of perceived behavioural control which takes into self - efficacy or people's belief in their own ability to perform or intention to perform a task. People are far more likely to intend to perform a task when they believe that they can do so successfully and have control of the behaviour.

\section{CP 4: Cooperative and Collaborative Behaviour}

Social dilemmas require a choice between cooperation or sacrificing for the greater good, and self-interest.

International Journal of Management and Applied Research, 2020, Vol. 7, No. 4 
Cooperation and collaboration are forms of working together with differing shades of meaning that are in some ways interchangeable with the purpose achieving agreed goals or outcomes. The ODE (2009) defines them as follows:

- Cooperation being described as working to together to achieve the same end.

- Collaboration as working with someone to produce something.

Both as concepts only appear to differ in organisational structure and format and are the basis of other concepts of working together like co-regulation (Martinez et al., 2007).

\section{CP 5: Functional, resilient, collective risk-based safety culture}

Good functional collective cultures enable everybody to contribute to maintaining, sustaining, and improving standards and resilience. Resilience is a concept concerned fundamentally with how a system, organisation, community or individual can deal with disturbance, surprise and change that is framing current thinking about sustainability with component parts to anticipate, absorb accommodate, or recover from the effects of a shock or stress in a timely and efficient manner (Mitchell and Harris, 2012).

\section{Discussion and Conclusion}

The factors and elements discussed that influence attitudes and behaviour and their impact on risk-based safety cultures is not exhaustive and there is no guarantee that a significant group of people, let alone the entire population, can put self-interest to one side and achieve an embedded positive collective and cooperative culture to deal effectively with the current pandemic. For example, people who have overriding economic difficulties, disbelief in science or a government's motives. This can lead to what De Cremer et al. (2008) describe as an interdependence situation or social dilemma in which people must decide to cooperate or defect. In these interdependence situations the dominant choice is to act in one's own best interest, because the individual's incentives for not cooperating are greater than for cooperating regardless of what others do.

However as suggested by Levy (2017), the use of nudges to reason that offers a choice of action rather than trying to force people can potentially produce better results, but more than nudges maybe required to persuade people to act in the collective interest. For example, in the form of direct economic help from the government.

\section{References}

1. Ajzen, I. and Fishbein, M. (1980), Understanding attitudes and predicting social behaviour. London: Prentice-Hall International Inc.

2. Ajzen, I. (1991), "The theory of planned behaviour", Organizational Behavior and Human Decision Processes, Vol. 50, No. 2, pp. 179211. https://doi.org/10.1016/0749-5978(91)90020-T

International Journal of Management and Applied Research, 2020, Vol. 7, No. 4 
Towards a Risk Based Cooperative and Collaborative Culture - the Attitudinal Elements and Influences that Shape Our Behaviour and Public Opinion

3. Balliet, D. and Van Lange, P. A. M. (2013), "Trust, conflict, and cooperation: A meta-analysis", Psychological Bulletin, Vol. 139, No. 5, pp. 1090-1112. https://doi.org/10.1037/a0030939

4. BBC News (2020), "Blackpool crowds ignore Covid 'last blast' warning”, $B B C$ [Online] Available from: https://www.bbc.co.uk/news/uk-england-lancashire54224544 [Accessed on 2 October 2020].

5. Bradford-Knox , R. (2008), The impact of cultural backgrounds on peoples' attitudes to their job status, food hygiene and its importance to public health, Master Dissertation, UK: University of Central Lancashire.

6. Bradford-Knox, R.; Kane, K. and Neighbour, S.(2016), "Approaches to Food Safety Hazard Control and Risk Management: A Case Study of Preston City Council's Food Safety Compliance Strategy", International Journal of Management and Applied Research, Vol. 3, No. 1, pp. 14-29. https://doi.org/10.18646/2056.31.16-002

7. Bradford-Knox, R. and Neighbour, S. (2020), "Food safety culture", FST Journal of Food Science and technology, Vol. 34, No. 1, pp. 32 -34. https://doi.org/10.1002/fsat.3401_9.x

8. Bruns, A.; Harrington, S. and Hurcombe, E. (2020), "Corona? 5G? or both?: the dynamics of COVID-19/5G conspiracy theories on Facebook", Media International Australia, Vol. 177, No. 1, pp. 12-29. https://doi.org/10.1177/1329878X20946113

9. Cronbach, L. J. and Meehl, P. E. (1955), "Construct validity in psychological tests", Psychological Bulletin, Vol. 52, No. 4, pp. 281302. https://doi.org/10.1037/h0040957

10. Cronemyr, P.; Backstrom, I. and Ronnback, A. (2017), "Quality culture deployment - using behaviours to explain, diagnose and improve a quality culture", International Journal of Quality and Services Sciences, Vol. 9, No. 3/4, pp. 498-518. https://doi.org/10.1108/IJQSS-02-2017-0008

11. De Cremer, D., Van Knippenberg, D., Van Dijk, E. and Van Leeuwen, E. (2008) "Cooperating If One's Goals Are Collective -Based: Social Identification Effects In Social Dilemmas as a Function of Goal Transformation", Journal of Applied Social Psychology, Vol. 38, No. 6, pp. 1562-1579. https://doi.org/10.1111/j.15591816.2008.00359.x

12. Ehrengren, L. and Hörnsten, B. (2011), "Performance and risk management in strategic cooperation: A comparative study of business and military sectors", International Journal of Productivity and Performance Management, Vol. 60, No. 4, pp. 387-403. https://doi.org/10.1108/17410401111123553

International Journal of Management and Applied Research, 2020, Vol. 7, No. 4 
Towards a Risk Based Cooperative and Collaborative Culture - the Attitudinal Elements and Influences that Shape Our Behaviour and Public Opinion

13. Fana, M.; Torrejón Pérez, S. and Fernández-Macías, E. (2020), "Employment impact of Covid-19 crisis: from short term effects to long terms prospects", Journal of Industrial and Business Economics, Vol. 47, No. 3, pp. 391-410. https://doi.org/10.1007/s40812-020-00168-5

14. Giammetti, R.; Papi, L. and Teobaldelli, D. (2020), "The Italian value chain in the pandemic: the input-output impact of Covid-19 lockdown", Journal of Industrial and Business Economics, Vol. 47, No. 3, pp. 483-497. https://doi.org/10.1007/s40812-020-00164-9

15. Health \& Safety Executive (2001), Reducing Risks: Protecting People, Norwich: Her Majesty's Stationery Office.

16. Hofstede, G. (2001), Cultures Consequences, $2^{\text {nd }}$ ed., Thousand Oaks: Sage.

17. Irwin, H. (1996), "The role of personal communication in technology transfer in the aerospace industry", Australian Journal of Communication, Vol. 23, No. 2, pp. 34-50.

18. Irwin, K. and Berigan, N., (2013), "Trust, Culture and Cooperation: A Social Dilemma Analysis of Pro-Environmental Behaviours", The Sociological Quarterly, Vol. 54, No. 3, pp. 424-449. https://doi.org/10.1111/tsq.12029

19. Jolley, D. and Paterson, J.L. (2020), "Pylons ablaze: Examining the role of 5G COVID-19 conspiracy beliefs and support for violence", British Journal of Social Psychology, Vol. 59, No. 3, pp. 628-640. https://doi.org/10.1111/bjso.12394

20. Kane, K. and Taylor, J. Z. (2018), "Integrating culture and management control: is it oil and water or salad dressing?", Worldwide Hospitality and Tourism Themes, Vol. 10, No. 3, pp. 382-390. https://doi.org/10.1108/WHATT-02-2018-0014

21. Levy, N. (2017), "Nudges in Post Truth World", Journal of Medical Ethics, Vol. 43, No. 8, pp. 495-500. http://doi.org/10.1136/medethics-2017-104153

22. Local Government Association (2013), Changing behaviours in public health - to nudge or to shove? [Online] Available from: https://www.local.gov.uk/sites/default/files/documents/changing-behaviours-publie0a.pdf [Accessed on $6^{\text {th }}$ August 2020].

23. MacKenzie, A. and Bhatt, I. (2020), "Lies, Bullshit and Fake News: Some Epistemological Concerns", Postdigital Science and Education, Vol. 2, No. 1, pp. 9-13. https://doi.org/10.1007/s42438-018-0025-4

24. Martinez, M.G., Fearne, A., Caswell, J.A. and Henson, S. (2007), "Co-regulation as a possible model for food safety governance: Opportunities for public-private partnerships", Food Policy, Vol. 32, No. 3, pp. 299-314. https://doi.org/10.1016/j.foodpol.2006.07.005

International Journal of Management and Applied Research, 2020, Vol. 7, No. 4 
Towards a Risk Based Cooperative and Collaborative Culture - the Attitudinal Elements and Influences that Shape Our Behaviour and Public Opinion

25. Mearns, K. and Flin, R. (1995), "Risk perception and attitudes to safety by personnel in the offshore oil and gas industry: a review", Journal Loss Prevention Process Industry, Vol. 8, No. 5, pp. 299-305. https://doi.org/10.1016/09504230(95)00032-V

26. Medeiros, L. C.; Hillers, V. N.; Chen, G.; Bergmann, V.; Kendall, P. and Schroeder, M. (2004), "Design \& development of food safety knowledge \& attitude scales for consumer food safety and education", Journal of the American Dietetic Association, Vol. 104, No. 11, pp. 1671-1677 https://doi.org/10.1016/j.jada.2004.08.030

27. Mitchell, T. and Harris, K. (2012), "Resilience; A risk management approach", Overseas Development Institute Working and Discussion Paper, [Online] Available from: https://www.odi.org/sites/odi.org.uk/files/odi-assets/publicationsopinion-files/7552.pdf [Accessed on $6^{\text {th }}$ October 2020].

28. Oxford English Dictionary (2020), "Opinion", Lexico [Online] Available from: https://www.lexico.com/definition/opinion [Accessed on $6^{\text {th }}$ October 2020].

29. Oxford Languages (2020), "Word of the Year 2016", Oxford University Press [Online] Available from: https://languages.oup.com/word-of-the-year/2016/ [Accessed on $6^{\text {th }}$ October 2020].

30. Strange, R. (2020), "The 2020 Covid-19 pandemic and global value chains", Journal of Industrial and Business Economics, Vol. 47, No. 3, pp. 455-465. https://doi.org/10.1007/s40812-020-00162-X

31. Sunstein, C. R. (2014), Why Nudge? The politics of Liberation Paternalism, London: Yale University Press.

International Journal of Management and Applied Research, 2020, Vol. 7, No. 4 